\title{
PREPARATION AND EVALUATION OF COPPER NANOPARTICLES LOADED HYDROGEL FOR BURNS
}

\author{
ASHISH KUMAR ${ }^{a, b}$, VINAY PANDITc, UPENDRA NAGAICHa ${ }^{*}$
}

aDepartment of Pharmaceutics, Amity Institute of Pharmacy, Amity University, Noida, Uttar Pradesh 201303, India, bAmity Institute of Pharmacy, Amity University, Haryana 122413, India, cDepartment Pharmaceutics, Laureate Institute of Pharmacy, Himachal Pradesh 177101, India

Email: upendra_nagaich@hotmail.com

Received: 19 Dec 2020, Revised and Accepted: 20 Jan 2021

\section{ABSTRACT}

Objective: The present study focuses on the development and optimization of copper nanoparticles (CNPs) loaded hydrogel for the treatment of dermal burn injuries.

Methods: CNPs gel was prepared by dispersing the variable concentration of polyvinylpyrrolidone (PVP K30) and hydroxypropyl methylcellulose (HPMC) in distilled water, PEG 400, and copper nanoparticles. factor screening study was performed for identification of influential factors, followed by optimization study using three-factor Box-Behnken design.

Results: Optimized nanogel formulation, when compared to normal control (NC), shows a significant reduction of pro-inflammatory cytokines (IL-6 $=39.74 \%$ and TNF- $\alpha=49.37 \%$ ) and increased level of anti-inflammatory cytokines (IL-10 $=30.90 \%)$, indicating reduced inflammation. Further, the wound closure rate of CNPs gel shows significant (12.27\%) wound closure as compared to the NC group and complete wound closure (100 \%) on the 14th day, indicating accelerated wound healing.

Conclusion: the present investigation endorses accelerated scar-free, accelerated wound healing potential of copper nanoparticles gel with antiinflammatory potential.

Keywords: Copper nanoparticles, Optimization, Hydrogel, Wound healing

(C) 2021 The Authors. Published by Innovare Academic Sciences Pvt Ltd. This is an open access article under the CC BY license (https://creativecommons.org/licenses/by/4.0/) DOI: https://dx.doi.org/10.22159/ijap.2021v13i2.40558. Journal homepage: https://innovareacademics.in/journals/index.php/ijap

\section{INTRODUCTION}

A burn is an injury to organic tissue or skin primarily due to heat, chemicals, friction, electricity, or radioactivity. Thermal or heat burns occur when organic tissue or skin gets damaged due to exposure to heat [1]. The healing of burn injury involves three phases. The inflammatory phase is the initial phase which consists of vascular response consisting of extravasation of plasma fluids, which requires fluid replacement, followed by the cellular response in which neutrophils and monocytes migrate to the site of injury. Later the level of neutrophils decreases and is replaced by macrophages, followed by the release of chemotactic factors like kallikreins and fibrin by the coagulation process [2]. Mast cells release tumor necrosis factor, histamine, protease, leukotrienes, and cytokines. The cellular response promotes phagocytosis and removal of dead tissue to promote the generation of healthy tissues. Remodeling phase, in partial-thickness burns proliferation phases, starts by reepithelization, in the form of keratinocyte migration from skin appendages with few hours of injury, which usually requires 5-7 d for complete wound coverage, followed by the formation of basement membrane zone between dermis and epidermis [3]. Angiogenesis and fibrogenesis promote the reconstruction of the dermis, followed by maturation of graft or scar. Initially, collagen and elastin deposit around the epithelial, endothelial, and smooth muscle in the form of an extracellular matrix. Finally, in the resolution phase. The extracellular matrix converts into mayo fibroblast phenotype, resulting in scar tissue contraction [4].

The current medical treatment for burn wound management includes immunization of the patient by tetanus prophylaxis, followed by the exercise of adherent dead tissue and necrotic tissue over the first several days. The cleaning of the burn wound is recommended by $0.25 \%$ chlorhexidine, $0.1 \%$ cetrimide solution, or any other mild non-alcoholic based antiseptic

To obtain the best formulation for the development of hydrogel with desirable mean release time (MRT), viscosity, swelling index, along with accelerated wound healing, the relationship between a controlled variable and quality variable must be understood. Traditionally we employ the method of "changing one variable at a time while keeping others at constant". By this approach, we need to screen each and individual combination of formulation, which proves laborious, expensive, and unfavorable for identifying and fixing unpredictable errors. In our approach, we employ the design of experiment (DOE) for obtaining crucial information for the understanding relationship between variables and response [5].

The objective of the study was the identification of formulation variables affecting characterization and wound healing property of hydrogel, using the response surface method (RSM). The objective of the study includes the optimization of polymer and copper nanoparticle concentration to obtain accelerated wound healing in burn wounds and optimize the factors that could affect the scaleup process or large-scale development [6]. The objective also includes a set guide for guidelines to eliminate the initial screening for the formulation and optimization of hydrogel from hydroxypropyl methylcellulose (HPMC) and Polyvinylpyrrolidone (PVP) for wound healing [7].

Copper nanoparticles were used as a model drug for the study. Responses such as mean release time, viscosity, wound healing days, and the swelling index was evaluated using Box-Behnken design (BBD).

\section{MATERIALS AND METHODS}

\section{Materials}

Copper nanoparticles were prepared in the previous publication [8], HPMC, PVP K30, and polyethylene glycol 400 (PEG-400) were purchased from a central drug house, New Delhi, India. All other chemicals were of analytical grade.

\section{Preparation of hydrogel}

The hydrogel was prepared by dispersing PVP K30 and HPMC into distilled water followed by continuous stirring for $1 \mathrm{~h}$. and allowed 
to soak overnight with $25 \mathrm{ml}$ distilled water in the refrigerator. PEG 400 was added and mixed. Finally, the copper nanoparticles were dispersed in the remaining distilled water and added to the gel mixture to make up the volume to $50 \mathrm{ml}$ [8].

\section{Visual evaluation of nanogel}

The physical appearance of nanogel formulation was a reddishbrown, homogeneously dispersed mixture and having a smooth texture.

\section{Factor screening studies}

A five-factor ten-run fractional factorial design was applied for factor screening studies to identify the most influential factors affecting nanogel properties. Table 1 shows the design matrix enlisting the studied factors.

Factor screening studies are based on the principle of "factor sparsity", where selected factors among numerous were identified to determine dominant experimental variation in the drug product. The "factors" accountable for significant variables were noted as the influential or active variable, while other factors were noted as lessinfluential factors or noise variables [9].
The factor screening studies were executed as a precursor to the formulation development for the identification of factors significantly affecting the response variables.

A five-factor Taguchi design was utilized for screening of influential factors involved in the development of nanogel and quantitative effect of its effect on critical quality attributes (CQA). Table 1 represents the individual high and low levels of variables in the formulation and the design matrix as per Taguchi's design. The MRT, viscosity, wound healing days, and swelling index was finalized as the key quality attributes for the investigation of highly influential formulation variables among the studied factors.

13 formulations were prepared by soaking the polymer into phosphate buffer saline and refrigerated overnight and the nanoparticles were dispersed into the gel for the formulation of nanogel. These formulations were subsequently characterized by forgoing key quality attributes.

The polynomial equation was obtained and the coefficient of individual factors corresponding to the response variable was analyzed by determining the interaction effect among the factors. The half-normal plot and Pareto charts were utilized for quantitative analysis of the influence of individual non-dependent variables on the formulation.

Table 1: Design matrix for screening for influential factors as per five-factor two-level for hydrogel

\begin{tabular}{|c|c|c|c|c|c|}
\hline Run & HPMC (\%) & PVP K30 (\%) & PEG-400 (\%) & CNPs conc $(\mu \mathrm{g} / \mathrm{ml})$ & CNP size (nm) \\
\hline 1 & 0.2 & 1 & 0.1 & 0.2 & 50 \\
\hline 2 & 0.1 & 5 & 2.5 & 0.2 & 50 \\
\hline 3 & 0.1 & 5 & 2.5 & 0.05 & 150 \\
\hline 4 & 0.2 & 1 & 0.1 & 0.05 & 150 \\
\hline 5 & 0.2 & 5 & 2.5 & 0.05 & 50 \\
\hline 6 & 0.2 & 1 & 2.5 & 0.2 & 150 \\
\hline 7 & 0.1 & 1 & 2.5 & 0.05 & 50 \\
\hline 8 & 0.2 & 5 & 0.1 & 0.2 & 150 \\
\hline 9 & 0.1 & 1 & 0.1 & 0.2 & 150 \\
\hline 10 & 0.1 & 5 & 0.1 & 0.05 & 50 \\
\hline
\end{tabular}

\section{Optimization of nanogel formulation}

Statistical optimization study of the nanogel formulation was carried out using BBD using Design-Expert software (Version 12) to obtain desirable formulation with specific characteristics. From the preoptimization study, different formulation parameters were selected for the optimization study. The independent variable includes HPMC (F1), PVP-K30 (F2), PEG-400 (F3), and CNPs conc (F4). The dependent variables for the optimization study were MRT (Y1), viscosity (Y2), wound healing days (Y3), and swelling index (Y4) as they have been the most influential factors to affect the dependent variables.

A three-factor, three-level BBD was selected for illustration of response surface nature in the experimental run for determination of optimal experiment combination. The level of each independent variable is shown in table 2 .

Table 2: Level of each independent variable used in CNG

\begin{tabular}{llll}
\hline Run & Independent variables & & \\
\cline { 2 - 3 } & HPMC (\%) & PVP-K30 (\%) & 0.125 \\
\hline 1 & 0.15 & 3 & 0.05 \\
2 & 0.15 & 1 & 0.125 \\
3 & 0.15 & 3 & 0.125 \\
4 & 0.1 & 1 & 0.125 \\
5 & 0.15 & 3 & 0.05 \\
6 & 0.1 & 3 & 0.125 \\
7 & 0.1 & 5 & 0.125 \\
8 & 0.15 & 3 & 0.05 \\
9 & 0.2 & 3 & 0.125 \\
10 & 0.2 & 1 & 0.125 \\
11 & 0.15 & 3 & 0.2 \\
12 & 0.15 & 5 & 0.2 \\
13 & 0.15 & 1 & 0.2 \\
15 & 0.2 & 3 & 0.2 \\
16 & 0.1 & 3 & 0.125 \\
& 0.2 & 5 & 0.05 \\
\end{tabular}


The independent variables were evaluated at three levels: low $(-1)$, basal (0), and high $(+1)$, with 17 sets of experimental runs of which 5 were in center point. Minimization of uncontrolled factors was done through the order of randomization. The experimental results were analyzed and fitted into a model, represented by an equation.

$$
\begin{aligned}
\mathrm{Y}=\beta_{0}+\beta_{1} \mathrm{~A}+\beta_{2} \mathrm{~B} & +\beta_{3} \mathrm{C}+\beta_{11} \mathrm{~A} 2+\beta_{22} \mathrm{~B} 2+\beta_{33} \mathrm{C} 2+\beta_{12} \mathrm{AB} \\
& +\beta_{13} \mathrm{AC}+\beta_{23} \mathrm{BC}
\end{aligned}
$$

Where: " $\mathrm{Y}$ " is the response; " $\mathrm{A}$ ", " $\mathrm{B}$ " and " $\mathrm{C}$ " are independent variables of HPMC, PVP K30, and CNPs conc, respectively. In the equation, $\beta_{0}$ constant represents intercept coefficient (center point regression coefficient); $\beta_{1}, \beta_{2}, \beta_{3}$ are single point variable (linear coefficient); whereas $\beta_{11}, \beta_{22}, \beta_{33}$ are double-action coefficient of individual factor (quadratic coefficients); and $\beta_{12}, \beta_{13}, \beta_{23}$ coefficient represents the extent of interaction. The regression model generated by the study was evaluated by analyzing the regression coefficient, analysis of variance, and $\mathrm{p}$ values. The second-order model was evaluated using Fisher's test and the model fit quality was determined using multiple coefficients of determination $\left(\mathrm{R}^{2}\right)$. Finally, the optimized formulation was determined using point prediction methods of software by response value constraint. The optimized formulation was further evaluated for spreadability test, in vitro compatibility studies, histological evaluation, estimation of inflammatory cytokines, and statistical analysis [10].

\section{In vitro release study}

In vitro release studies of the prepared nanogel were done with the help of modified dissolution apparatus. $2 \mathrm{~g}$ of the nanogel was placed in the open-end cylinder tube having a diameter of $3.2 \mathrm{~cm}$ is tied with a semi-permeable membrane which is soaked overnight in phosphate buffer saline having $\mathrm{pH}$ 7.4. Finally, the apparatus was suspended into a beaker containing dissolution medium $\left(37 \pm 2{ }^{\circ} \mathrm{C}, 50 / \mathrm{min}\right) 1 \mathrm{ml}$ of periodic sampling. The aliquots were analyzed by flame atomic absorption spectrophotometer for the copper ions concentration [11].

\section{Mean release time}

Mean release time is the time duration taken by the formulation to release $80 \%$ of the active pharmaceutical agent.

Mean release time of the formulation was determined using the equation

$$
\operatorname{MRT}=\frac{\sum_{1}^{\mathrm{t}} \mathrm{tmid}^{\Delta \mathrm{C}}}{\sum_{1}^{\mathrm{t}} \Delta \mathrm{C}}
$$

Where: "tmid" is the midpoint between initial and final time " $\mathrm{t}$ ", "t-1"; " $\Delta C$ " represents the change in concentration between " $t$ " and " $t-1$ ".

\section{Viscosity study}

$1 \mathrm{~g}$ of nanogel was taken in a beaker and $10 \mathrm{ml}$ distilled water was added and allowed to soak overnight. The resultant mixture was thoroughly mixed to obtain a homogeneous mixture. The viscosity of nanogel was determined using Brookfield viscometer (LV DV$\mathrm{II}+$ Pro) at $0.5,1,2.5,5,10,20,30,50,60$, and 100/min (Spindle no, 64) with increase revolution speed and vice versa at $27{ }^{\circ} \mathrm{C}$ Consistency index and flow index were measured using the formula:

$$
\tau=\mathrm{Kr}^{\mathrm{n}}
$$

Taking log on both sides

$$
\log \tau=\log \mathrm{K}+\mathrm{nlog} \mathrm{R}
$$

Where: " $\tau$ " is shear stress; " $K$ " is consistency index; " $r$ " is the shear rate; " $\mathrm{n}$ " is flow index.

\section{Swelling index}

1g nanogel samples were dried in a hot air oven for $12 \mathrm{~h}$ at $60^{\circ} \mathrm{C}$. Dried nanogel was then placed in phosphate buffer saline $\mathrm{pH} 7.4,37$ ${ }^{\circ} \mathrm{C}$ ) and is allowed to swell for $6 \mathrm{~h}$ and weighed. The swelling index of the nanogel was determined using the equation:

$$
\text { Swelling index }=\frac{W s}{W a} \times 100
$$

Where: "Ws" is the weight of nanogel after soaking; "Wa" is the weight of nanogel sample soaked in PBS until a constant weight is achieved [12].

\section{Animal maintenance}

Wistar rats (230-250 g) of either sex were used in the study. All the animals were approved by the institutional animal ethical committee (Approval no. CPCSEA/IAEC/AIP/2016/04/13, Amity University, L-1 Block, Noida. The animals were acclimatized before experimentation in the animal experimentation room $\left(20 \pm 2{ }^{\circ} \mathrm{C}\right.$, $60 \pm 10$ humidity) at normal day-night cycle, with normal rat chow and water ad libitum.

\section{Creation of burn wound}

Animals were anesthetized with ketamine and xylazine (80 and 10 $\mathrm{mg} / \mathrm{kg}$ I. P.). The dorsal region of the animal was shaved and sterilized with isopropyl alcohol surgical scrub. Burn wound was created aseptically at the dorsal region of the animal, using a heated metal road $\left(100-130{ }^{\circ} \mathrm{C}\right)$ having a diameter of $13 \mathrm{~mm}$. A burn wound was created by placing the heated metal rod for $5 \mathrm{~s}$ at the interscapular region of the rat dorsal area. Epithelial burn wound was covered using non-woven polyester dressing [13].

\section{Estimation of epithelization period}

Burn wound epithelialization period was measured by measuring the burn wound contraction by vernier caliper. The epithelization period was measured by measuring the rate of wound contraction, which is expressed below.

$\%$ wound contraction rate
$=\frac{\text { (Initial wound diamater }- \text { Wound diameter at specific date) }}{\text { Initial wound diameter }} \times 100$

\section{Histological evaluation}

Three rats from each group were sacrificed on the $5^{\text {th }}$ and $14^{\text {th }} \mathrm{d}$ of experimentation. Section of burn wound was evaluated using hematoxylin and eosin staining for evaluation of re-epithelization, fibroblast accumulation, collagen, and polymorphonuclear formation using inverted optical microscopes.

\section{Estimation of inflammatory cytokines}

Wound healing rate is dependent on a delicate balance of antiinflammatory interleukin (IL) 10 and pro-inflammatory, IL-6 and Tumor necrosis factor (TNF)- $\alpha$. Sampling was done on the $5^{\text {th }}$ and $14^{\text {th }} \mathrm{d}$ followed by separation of serum from the blood for estimation of serum IL-10, IL-6, and TNF- $\alpha$ using enzyme-linked immunoassay.

\section{Statistical analysis}

All the values were expressed in mean \pm SD. All biochemical evaluation data were analyzed using one-way ANOVA followed by Tuckey test post-hoc analysis.

\section{RESULTS AND DISCUSSION}

\section{Visual evaluation of nanoge}

The physical appearance of the nanogel formulation was reddishbrown, a homogeneously dispersed mixture having a smooth texture.

\section{Factorial screening studies}

The performance of nanogel formulation as a delivery system depends on various formulation variables, which may influence each other. Hence it becomes complex to study the effect of individual variables and the effect of the combination through the traditional approach. Hence, it is extremely crucial to use an $\mathrm{FbD}$ based approach to be able to identify the desirable levels of variables with optimal attributes. In this study, we observed various formulation variables potentially influencing response variables of nanogel formulation was performed by applying Taguchi screening design for five factors at two levels. This design helps in the identification of the most significant factors for detailed investigation using minimal experimentation, which leads to a significant saving of materials, effort, and time. The screening method's principally is based on the "sparsity effect" phenomenon, i.e., only a limited factor is responsible for most product characteristics and can explain a significant section of experimental validation and are known as influential factors. While others are known as less influential factors. 

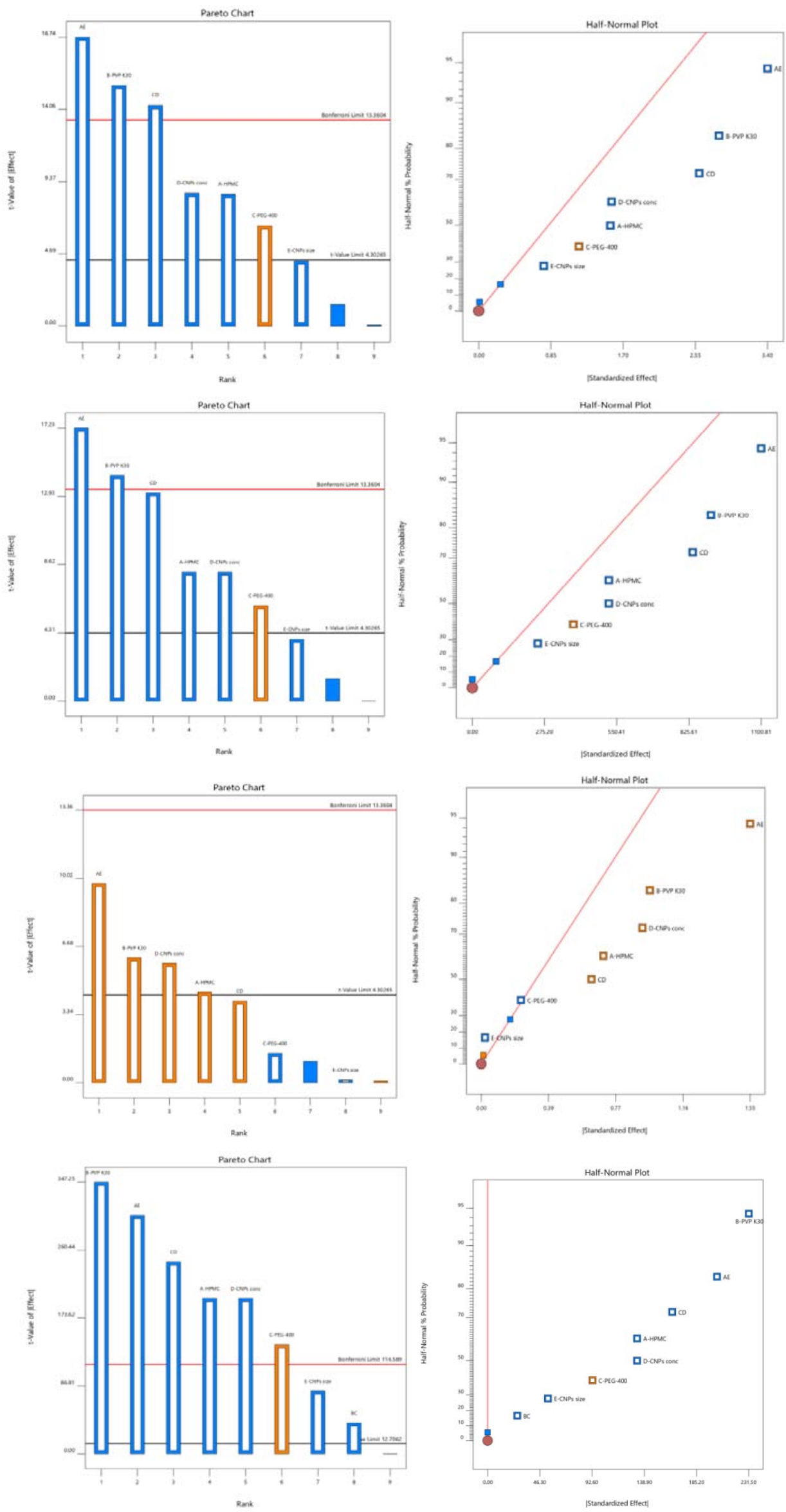

Fig. 1: Pareto and half normal charts showing the effect of (A) HPMC concentration, (B) PVP K30 concentration, (C) PEG-440, (D) CNPs conc, and (E) CNPs size on studied response variables for copper nanoparticles loaded hydrogel 


\section{Model generation}

Screening predicts significant approximation to the combination of various factors without interaction. Taguchi design was employed for the screening studies. The design has the advantage of requiring minimal (i.e. 10) runs for large numbers (i.e. 5) of independent variables.

The first order equation generated for response variables is represented by equation 1

$$
y=\beta_{0}+\beta_{1} X_{1}+\beta_{2} X_{2}+\beta_{3} X_{3}+\beta_{4} X_{4}+\beta_{5} X_{5}
$$

Five coefficients $\left(\beta_{1}-\beta_{7}\right)$ were calculated with $\beta_{0}$ as an intercept for the general polynomial equation. For each response variable, the first order mathematical model generated was having $\mathrm{P}<0.005$, which is significant. The coefficients which were found to be highly significant were selected for further study. The $\mathrm{R}^{2}$ values of all the response variables are quite high, indicating an excellent fit to experimental data.

\section{Model analysis}

As described in fig. 1, HPMC (A), PVP K30 (B), and CNPs (D) exert a significant positive effect on the response MRT, viscosity, wound healing, and swelling index. Thus, they were chosen as three influential factor variables for nanogel formulation.

\section{Systemic optimization studies}

The objective of the screening study is the identification of influential factors and the execution of less influential factors. Thus, minimizing the required number of experimentations while maintaining high predictability of the experimental outcome. The experimental data was obtained by BBD in which influential factors were optimized, keeping other less influential factors at their best level. It describes the different levels of variables and the response of trials conducted according to BBD.

A total of 17 experiments were carried out with 5 center points for the study of the effect of formulation factors (table 4) affecting MRT, viscosity, wound healing, and swelling index. Experimental run response data by BBD.

Table 4: The combination of various factors used in CNG and responses

\begin{tabular}{|c|c|c|c|c|c|c|c|}
\hline Run & $\begin{array}{l}\text { Factor A: } \\
\text { HPMC (\%) }\end{array}$ & $\begin{array}{l}\text { Factor B: PVP } \\
\text { K30 (\%) }\end{array}$ & $\begin{array}{l}\text { Factor C: CNP } \\
\text { conc }(\mu \mathrm{g} / \mathrm{ml})\end{array}$ & $\begin{array}{l}\text { Response 1: } \\
\text { MRT (h) }\end{array}$ & $\begin{array}{l}\text { Response 2: } \\
\text { Viscosity (m. Pa. S) }\end{array}$ & $\begin{array}{l}\text { Response 3: } \\
\text { Wound healing (d) }\end{array}$ & $\begin{array}{l}\text { Response 4: } \\
\text { Swelling index (\%) }\end{array}$ \\
\hline 1 & 0.15 & 3 & 0.125 & 11.9 & 3925 & 13.097 & 961 \\
\hline 2 & 0.15 & 1 & 0.05 & 6.908 & 2481 & 15.3 & 592 \\
\hline 3 & 0.15 & 3 & 0.125 & 11.905 & 3930 & 13.093 & 961 \\
\hline 4 & 0.1 & 1 & 0.125 & 6.402 & 2312 & 15.6 & 549 \\
\hline 5 & 0.15 & 3 & 0.125 & 11.9 & 3930 & 13.1 & 960 \\
\hline 6 & 0.1 & 3 & 0.05 & 11.4 & 3761 & 13.8 & 919 \\
\hline 7 & 0.1 & 5 & 0.125 & 14.4 & 4899 & 12.6 & 1197 \\
\hline 8 & 0.15 & 3 & 0.125 & 11.903 & 3927 & 13.1 & 959 \\
\hline 9 & 0.2 & 3 & 0.05 & 12.2 & 4033 & 13 & 996 \\
\hline 10 & 0.2 & 1 & 0.125 & 7.2 & 2583 & 14.8 & 629 \\
\hline 11 & 0.15 & 3 & 0.125 & 11.9 & 3943 & 13.1 & 964 \\
\hline 12 & 0.15 & 5 & 0.2 & 15 & 5068 & 11.997 & 1243 \\
\hline 13 & 0.15 & 1 & 0.2 & 7 & 2477 & 15 & 591 \\
\hline 14 & 0.2 & 3 & 0.2 & 12.3 & 4027 & 12.697 & 1002 \\
\hline 15 & 0.1 & 3 & 0.2 & 11.503 & 3763 & 13.495 & 923 \\
\hline 16 & 0.2 & 5 & 0.125 & 15.2 & 5169 & 11.8 & 1278 \\
\hline 17 & 0.15 & 5 & 0.05 & 14.906 & 5073 & 12.293 & 1240 \\
\hline
\end{tabular}

The response obtained from this study is modeled into the quadratic function of the independent variables: the first-order polynomial equation was employed for approximating the functions.

$$
\begin{gathered}
\mathrm{y}=\beta_{0}+\beta_{1} \mathrm{X}_{1}+\beta_{2} \mathrm{X}_{2}+\beta_{3} \mathrm{X}_{3}+\beta_{4} \mathrm{X}_{1} \mathrm{X}_{2}+\beta_{5} \mathrm{X}_{1} \mathrm{X}_{3}+\beta_{6} \mathrm{X}_{2} \mathrm{X}_{3}+\beta_{7} \mathrm{X}_{1}^{2}+ \\
\beta_{8} \mathrm{X}_{2}^{2}+\beta_{9} \mathrm{X}_{3}^{2}(2)
\end{gathered}
$$

Where: " $\beta$ " is coefficient, and " $\mathrm{X}$ " is independent variables.

The value of response y1 (MRT), y2 (viscosity), y3 (wound healing days), and y4 (swelling index) ranges from 6.4-15.2, 2312-5169,
11.8-15.6, and 549-1278. The ratio of maximum and minimum value for response is $2.37,2.23,1.32$, and 2.32 , respectively. Therefore, the obtained values do not require power transformation.

The model selection for response analysis (table 5) was done based on the sequential model sum of squares, lack of fit test, and model summary statistics. The probe $>\mathrm{F}$ value of $\mathrm{P}<0.0001$, low standard deviation, high R-square value, and lower predicted residual error sum of square (PRESS) value indicate the quadratic model for

\begin{tabular}{|c|c|c|c|c|c|c|c|c|c|c|c|c|c|c|c|c|}
\hline \multirow[t]{2}{*}{ Source } & \multicolumn{4}{|c|}{ R-squared } & \multicolumn{4}{|c|}{ Adjusted R-squared } & \multicolumn{4}{|c|}{ Predicted R-squared } & \multicolumn{4}{|c|}{ PRESS } \\
\hline & $\mathrm{y1}$ & y2 & y3 & $\mathrm{y4}$ & $\mathrm{y} 1$ & $\mathrm{y} 2$ & y3 & y4 & y1 & $\mathrm{y} 2$ & y3 & $\mathrm{y4}$ & y1 & $\mathrm{y} 2$ & y3 & y4 \\
\hline \multicolumn{17}{|c|}{ Model summary statistics } \\
\hline \multirow[t]{2}{*}{ Linear } & 0.96 & 0.99 & 0.94 & 0.98 & 0.96 & 0.99 & 0.93 & 0.98 & 0.94 & 0.98 & 0.90 & 0.98 & 7.83 & $1.924 \mathrm{E}$ & 1.96 & 16279. \\
\hline & 78 & 19 & 41 & 97 & 03 & 00 & 12 & 73 & 13 & 59 & 50 & 12 & & +05 & & 91 \\
\hline \multirow[t]{2}{*}{$2 \mathrm{FI}$} & 0.96 & 0.99 & 0.94 & 0.98 & 0.94 & 0.98 & 0.91 & 0.98 & 0.87 & 0.97 & 0.80 & 0.95 & 17.2 & $4.058 \mathrm{E}$ & 4.05 & 35955. \\
\hline & 78 & 19 & 41 & 97 & 84 & 70 & 06 & 36 & 11 & 03 & 40 & 84 & 2 & +05 & & 91 \\
\hline Quadra & 1.00 & 1.00 & 1.00 & 1.00 & 1.00 & 1.00 & 1.00 & 0.99 & 1.00 & 1.00 & 1.00 & 0.99 & 0.00 & 609.37 & 0.00 & 217.88 \\
\hline & 00 & 00 & 00 & 00 & 00 & 00 & 00 & 99 & 00 & 00 & 00 & 97 & 06 & & 06 & \\
\hline \multirow[t]{2}{*}{ Cubic } & 1.00 & 1.00 & 1.00 & 1.00 & 1.00 & 0.99 & 1.00 & 0.99 & & & & & & & & \\
\hline & 00 & 00 & 00 & 00 & 00 & 99 & 00 & 99 & & & & & & & & \\
\hline
\end{tabular}
analyzing responses.

Table 5: Model summary statistics of responses

ANOVA was employed for the determination of the significance and magnitude of individual variables on another variable. The ANOVA (table 6) verifies the adequacy of the quadratic model (model Probe $>\mathrm{F}$ is less than 0.05-0.0001), it helps in the identification of factors affecting the response $\mathrm{y} 1-\mathrm{y} 4$ of nanogel, for MRT the ratio of
HPMC and PVP K30 were identified as significant, whereas for viscosity, HPMC, and PVP K30 were identified as significant, whereas for wound healing days, HPMC, PVP-K30, and CNP conc were observed as significant. In the case of swelling index HPMC and PVP were determined as significant factors. 
Table 6: ANOVA response for the surface model of MRT, viscosity, wound healing, and swelling index

\begin{tabular}{|c|c|c|c|c|c|c|c|c|c|c|c|c|c|c|c|c|}
\hline \multirow{2}{*}{$\begin{array}{l}\text { Sourc } \\
\text { e }\end{array}$} & \multicolumn{4}{|c|}{ Sum of squares } & \multicolumn{4}{|c|}{ df } & \multicolumn{4}{|l|}{ F value } & \multicolumn{4}{|c|}{ Prob>F P-value } \\
\hline & y1 & y2 & y3 & y4 & $\begin{array}{l}\mathbf{y} \\
1 \\
\end{array}$ & $\begin{array}{l}\mathbf{y} \\
2 \\
\end{array}$ & $\begin{array}{l}\mathbf{y} \\
3\end{array}$ & $\begin{array}{l}y \\
4 \\
\end{array}$ & y1 & y2 & y3 & y4 & y1 & y2 & y3 & y4 \\
\hline Model & $\begin{array}{l}133.5 \\
7\end{array}$ & $\begin{array}{l}1.366 \mathrm{E}+ \\
07\end{array}$ & 20.64 & $\begin{array}{l}8.645 \mathrm{E}+ \\
05\end{array}$ & 9 & 9 & 9 & 9 & $\begin{array}{l}1.808 \mathrm{E}+ \\
06\end{array}$ & $\begin{array}{l}49021.4 \\
5\end{array}$ & $\begin{array}{l}2.327 \mathrm{E}+ \\
05\end{array}$ & $\begin{array}{l}25614.7 \\
2\end{array}$ & $\begin{array}{l}<0.00 \\
01\end{array}$ & $\begin{array}{l}<0.00 \\
01\end{array}$ & $\begin{array}{l}<0.00 \\
01\end{array}$ & $\begin{array}{l}<0.00 \\
01\end{array}$ \\
\hline A & 1.28 & $\begin{array}{l}1.450 \mathrm{E}+ \\
05\end{array}$ & 1.28 & $\begin{array}{l}12561.1 \\
3\end{array}$ & 1 & 1 & 1 & 1 & $\begin{array}{l}1.555 \mathrm{E}+ \\
05\end{array}$ & 4682.53 & $\begin{array}{l}1.297 \mathrm{E}+ \\
05\end{array}$ & 3349.63 & $\begin{array}{l}<0.00 \\
01\end{array}$ & $\begin{array}{l}<0.00 \\
01\end{array}$ & $\begin{array}{l}<0.00 \\
01\end{array}$ & $\begin{array}{l}<0.00 \\
01\end{array}$ \\
\hline B & $\begin{array}{l}127.9 \\
7\end{array}$ & $\begin{array}{l}1.341 \mathrm{E}+ \\
07\end{array}$ & 18.03 & $\begin{array}{l}8.431 \mathrm{E}+ \\
05\end{array}$ & 1 & 1 & 1 & 1 & $\begin{array}{l}1.559 \mathrm{E}+ \\
07\end{array}$ & $\begin{array}{l}4.329 \mathrm{E}+ \\
05\end{array}$ & $\begin{array}{l}1.829 \mathrm{E}+ \\
06\end{array}$ & $\begin{array}{l}2.248 \mathrm{E}+ \\
05\end{array}$ & $\begin{array}{l}<0.00 \\
01\end{array}$ & $\begin{array}{l}<0.00 \\
01\end{array}$ & $\begin{array}{l}<0.00 \\
01\end{array}$ & $\begin{array}{l}<0.00 \\
01\end{array}$ \\
\hline $\mathrm{C}$ & $\begin{array}{l}0.018 \\
9\end{array}$ & 21.13 & $\begin{array}{l}0.181 \\
2\end{array}$ & 18.00 & 1 & 1 & 1 & 1 & 2304.71 & 0.6822 & $\begin{array}{l}18382.8 \\
1\end{array}$ & 4.80 & $\begin{array}{l}<0.00 \\
01\end{array}$ & $\begin{array}{l}0.436 \\
1\end{array}$ & $\begin{array}{l}<0.00 \\
01\end{array}$ & $\begin{array}{l}0.064 \\
6\end{array}$ \\
\hline $\mathrm{AB}$ & $\begin{array}{l}1.000 \\
\text { E-06 }\end{array}$ & 0.2500 & $\begin{array}{l}0.000 \\
0\end{array}$ & 0.2500 & 1 & 1 & 1 & 1 & 0.1218 & 0.0081 & 0.0000 & 0.0667 & $\begin{array}{l}0.737 \\
3\end{array}$ & $\begin{array}{l}0.930 \\
9\end{array}$ & $\begin{array}{l}1.000 \\
0\end{array}$ & $\begin{array}{l}0.803 \\
7\end{array}$ \\
\hline $\mathrm{AC}$ & $\begin{array}{l}2.250 \\
\text { E-06 }\end{array}$ & 16.00 & $\begin{array}{l}1.000 \\
\text { E-06 }\end{array}$ & 1.0000 & 1 & 1 & 1 & 1 & 0.2742 & 0.5167 & 0.1014 & 0.2667 & $\begin{array}{l}0.616 \\
7\end{array}$ & $\begin{array}{l}0.495 \\
5\end{array}$ & $\begin{array}{l}0.759 \\
4\end{array}$ & $\begin{array}{l}0.621 \\
5\end{array}$ \\
\hline $\mathrm{BC}$ & $\begin{array}{l}1.000 \\
\text { E-06 }\end{array}$ & 0.2500 & $\begin{array}{l}4.000 \\
\text { E-06 }\end{array}$ & 4.00 & 1 & 1 & 1 & 1 & 0.1218 & 0.0081 & 0.4058 & 1.07 & $\begin{array}{l}0.737 \\
3\end{array}$ & $\begin{array}{l}0.930 \\
9\end{array}$ & $\begin{array}{l}0.544 \\
4\end{array}$ & $\begin{array}{l}0.336 \\
1\end{array}$ \\
\hline $\mathrm{A}^{2}$ & $\begin{array}{l}0.043 \\
7\end{array}$ & 5011.58 & $\begin{array}{l}0.043 \\
2\end{array}$ & 19.01 & 1 & 1 & 1 & 1 & 5329.74 & 161.85 & 4379.00 & 5.07 & $\begin{array}{l}<0.00 \\
01\end{array}$ & $\begin{array}{l}<0.00 \\
01\end{array}$ & $\begin{array}{l}<0.00 \\
01\end{array}$ & $\begin{array}{l}0.059 \\
0\end{array}$ \\
\hline $\mathrm{B}^{2}$ & 4.20 & $\begin{array}{l}1.021 \mathrm{E}+ \\
05\end{array}$ & 1.06 & 8764.80 & 1 & 1 & 1 & 1 & $\begin{array}{l}5.122 \mathrm{E}+ \\
05\end{array}$ & 3298.61 & $\begin{array}{l}1.071 \mathrm{E}+ \\
50\end{array}$ & 2337.28 & $\begin{array}{l}<0.00 \\
01\end{array}$ & $\begin{array}{l}<0.00 \\
01\end{array}$ & $\begin{array}{l}<0.00 \\
01\end{array}$ & $\begin{array}{l}<0.00 \\
01\end{array}$ \\
\hline $\mathrm{C}^{2}$ & $\begin{array}{l}0.011 \\
0\end{array}$ & 1.05 & $\begin{array}{l}0.010 \\
0\end{array}$ & 5.33 & 1 & 1 & 1 & 1 & 1338.32 & 0.0340 & 1015.16 & 1.42 & $\begin{array}{l}<0.00 \\
01\end{array}$ & $\begin{array}{l}0.858 \\
9\end{array}$ & $\begin{array}{l}<0.00 \\
01\end{array}$ & $\begin{array}{l}0.272 \\
1\end{array}$ \\
\hline $\begin{array}{l}\text { Resid } \\
\text { ual }\end{array}$ & $\begin{array}{l}0.000 \\
1\end{array}$ & 216.75 & $\begin{array}{l}0.000 \\
1\end{array}$ & 26.25 & 7 & 7 & 7 & 7 & & & & & & & & \\
\hline $\begin{array}{l}\text { Lack } \\
\text { of fit }\end{array}$ & $\begin{array}{l}0.000 \\
0\end{array}$ & 18.75 & $\begin{array}{l}0.000 \\
0\end{array}$ & 12.25 & 3 & 3 & 3 & 3 & 2.28 & 0.1263 & 1.09 & 1.17 & $\begin{array}{l}0.221 \\
3\end{array}$ & $\begin{array}{l}0.939 \\
7\end{array}$ & & $\begin{array}{l}0.426 \\
2\end{array}$ \\
\hline $\begin{array}{l}\text { Pure } \\
\text { error }\end{array}$ & $\begin{array}{l}0.000 \\
0\end{array}$ & 198.00 & $\begin{array}{l}0.000 \\
0\end{array}$ & 14.00 & 4 & 4 & 4 & 4 & & & & & & & & \\
\hline $\begin{array}{l}\text { Cor } \\
\text { total } \\
\end{array}$ & $\begin{array}{l}133.5 \\
7 \\
\end{array}$ & $\begin{array}{l}1.366 \mathrm{E}+ \\
07\end{array}$ & 20.64 & $\begin{array}{l}8.645 \mathrm{E}+ \\
05\end{array}$ & $\begin{array}{l}1 \\
6 \\
\end{array}$ & $\begin{array}{l}1 \\
6 \\
\end{array}$ & $\begin{array}{l}1 \\
6 \\
\end{array}$ & $\begin{array}{l}1 \\
6 \\
\end{array}$ & & & & & & & & \\
\hline
\end{tabular}

Table 7: Values of regression term for responses

\begin{tabular}{|c|c|c|c|c|c|}
\hline \multirow[t]{2}{*}{ S. No. } & \multirow[t]{2}{*}{ Terms } & \multicolumn{4}{|l|}{ Values } \\
\hline & & y1 & y2 & y3 & y4 \\
\hline 1 & $\mathrm{R}^{2}$ & 1.0000 & 1.0000 & 1.0000 & 1.0000 \\
\hline 2 & Adjusted $\mathrm{R}^{2}$ & 1.0000 & 1.0000 & 1.0000 & 0.9999 \\
\hline 3 & Predicted $\mathrm{R}^{2}$ & 1.0000 & 1.0000 & 1.0000 & 0.9997 \\
\hline 4 & Adeq Precision & 4004.0554 & 669.7213 & 1578.9234 & 490.4993 \\
\hline
\end{tabular}

In table 7, the "Pred R-squared" value of their response was found to be in reasonable agreement and compared to "Adj R-squared" value, indicating model high predictability of response.

The final coded mathematical model as determined by DesignExpert software is presented in Equation no. 3-6 below for response y1-y4, respectively.

$\mathrm{y} 1(\mathrm{MRT})=11.90+0.3994 * \mathrm{~A}+4.00 * \mathrm{~B}+0.0486 * \mathrm{C}+0.0005 *$ $\mathrm{AB}-0.0007 * \mathrm{AC}+0.0005 * \mathrm{BC}-0.1019 * \mathrm{~A}^{2}-0.9992 * \mathrm{~B}^{2}+0.0511 *$ $\mathrm{C}^{2}(3)$

$\mathrm{y} 2($ Viscosity $)=3931.00+134.63 * \mathrm{~A}+1294.50 * \mathrm{~B}-1.62 *$ $\mathrm{C}-0.2500 * \mathrm{AB}-2.00 * \mathrm{AC}-0.2500 * \mathrm{BC}-34.50 * \mathrm{~A}^{2}-155.75 * \mathrm{~B}^{2}-$ $0.5000 * C^{2}(4)$

y3 (Wound healing days) $=13.10-0.3997 * \mathrm{~A}-1.50 * \mathrm{~B}-0.1505 *$ $\mathrm{C}+0.0000 * \mathrm{AB}+0.0005 * \mathrm{AC}+0.0010 * \mathrm{BC}+0.1012 * \mathrm{~A}^{2}+$ $0.5007 * \mathrm{~B}^{2}+0.0488 * \mathrm{C}^{2}(5)$

y4 (Swelling index) $=961.00+39.63 * \mathrm{~A}+324.63 * \mathrm{~B}+1.50 *$ $\mathrm{C}+0.2500 * \mathrm{AB}+0.5000 * \mathrm{AC}+1.0000 * \mathrm{BC}-2.13 * \mathrm{~A}^{2}-45.63 *$ $\mathrm{B}^{2}+1.13 * \mathrm{C}^{2}(6)$

A positive sign suggests a synergistic effect while a negative sign suggests an antagonistic effect. In case of y1 positive coefficient of $A, B$, and $C$ indicates increase in MRT with an increase in factors, while negative coefficient of $A C, A^{2}$, and $B^{2}$ indicates decreased in MRT with combination of factor AC and high concentration of $\mathrm{A}$ and $B$, for $y 2$ response, the positive coefficient of factor $A$ and $B$ indicates an increase in viscosity of nanogel with increase in concentration of factor $A$ and $B$, while the negative coefficient of $C, A B, A C, B C, A^{2}, B^{2}$, and $C^{2}$ indicate decrease in viscosity at high concentration of factor $C$ and combination of factors $\mathrm{AB}, \mathrm{AC}, \mathrm{BC}$, and high levels of factor $\mathrm{A}, \mathrm{B}, \mathrm{C}$.

In the case of response $\mathrm{y} 3$, the negative coefficient of factor $\mathrm{A}, \mathrm{B}$, and $\mathrm{C}$ indicate a decrease in days required for complete wound healing and the positive coefficient of the combination of factors $\mathrm{AB}, \mathrm{AC}, \mathrm{BC}, \mathrm{A}^{2}, \mathrm{~B}^{2}$, and $\mathrm{C}^{2}$ indicates a slight increase in the required number of wound healing days, when the factors are combined or at higher concentration.

In case of response $y 4$, the positive coefficient of $A, B, C, A B, A C, B C$, $\mathrm{B}^{2}$, and $\mathrm{C}^{2}$ indicates an increase in swelling index with an increase in the concentration of factor $\mathrm{A}, \mathrm{B}, \mathrm{C}$, and their combination with a higher concentration of individual polymer. Whereas the negative coefficient of $\mathrm{A}^{2}$ indicates the decrease in swelling index with higher levels of factor A. The experimental values were compared with theoretical values by diagnostic case statistic reports table 8 , indicating reasonably close agreement. The perturbation graph was plotted for the identification of the most influential factors. A higher slope indicates more influence of factor on the response as compared to the relatively flat line. In the case of response y1 (MRT), factor B shows a steep slope as compared to factor $\mathrm{A}$ and $\mathrm{C}$, indicating a significant influence on the response y1 as compared to other factors. In case of response y2. The steep slope of factor B as compared to factor $\mathrm{A}$ and $\mathrm{C}$ indicate a significant influence of factor $\mathrm{B}$ on response y2 as compared to other factors A and C.

In the case of response y3 (wound healing days) the steep slope of factor $B$ and slight slope of factor $A$ indicates a significant effect of factor $\mathrm{B}$ and $\mathrm{A}$ on response $\mathrm{y} 3$ as compared to factor $\mathrm{C}$.

In the case of response y4 (swelling index) the steep slope of factor $B$ and slight slope of factor A indicates the significant influence of factor A and B on response $\mathrm{y} 4$ as compared to factor $\mathrm{C}$. based on ANOVA and perturbation. 
Table 8: Actual and predicted value of responses y1-y4

\begin{tabular}{|c|c|c|c|c|c|c|c|c|c|c|c|c|}
\hline \multirow{2}{*}{$\begin{array}{l}\begin{array}{l}\text { Std } \\
\text { order }\end{array} \\
1\end{array}$} & \multicolumn{4}{|c|}{ Actual value } & \multicolumn{4}{|c|}{ Predicted value } & \multicolumn{4}{|c|}{ Residual } \\
\hline & 11.90 & 3925.00 & 13.10 & 961.00 & 11.90 & 3931.00 & 13.10 & 961.00 & -0.0016 & -6.00 & -0.0010 & 0.0000 \\
\hline 2 & 6.91 & 2481.00 & 15.30 & 592.00 & 6.91 & 2481.62 & 15.30 & 591.37 & 0.0021 & -0.6250 & -0.0002 & 0.6250 \\
\hline 3 & 11.90 & 3930.00 & 13.09 & 961.00 & 11.90 & 3931.00 & 13.10 & 961.00 & 0.0034 & -1.0000 & -0.0050 & 0.0000 \\
\hline 4 & 6.40 & 2312.00 & 15.60 & 549.00 & 6.40 & 2311.37 & 15.60 & 549.25 & -0.0001 & 0.6250 & -0.0010 & -0.2500 \\
\hline 5 & 11.90 & 3930.00 & 13.10 & 960.00 & 11.90 & 3931.00 & 13.10 & 961.00 & -0.0016 & -1.0000 & 0.0020 & -1.0000 \\
\hline 6 & 11.40 & 3761.00 & 13.80 & 919.00 & 11.40 & 3761.00 & 13.80 & 919.37 & -0.0020 & 0.0000 & 0.0012 & -0.3750 \\
\hline 7 & 14.40 & 4899.00 & 12.60 & 1197.00 & 14.40 & 4900.88 & 12.60 & 1198.00 & -0.001 & -1.88 & 0.0015 & -1.00 \\
\hline 8 & 11.90 & 3927.00 & 13.10 & 959.00 & 11.90 & 3931.00 & 13.10 & 961.00 & 0.0014 & -4.00 & 0.0020 & -2.00 \\
\hline 9 & 12.20 & 4033.00 & 13.00 & 996.00 & 12.20 & 4034.25 & 13.00 & 997.63 & -0.0023 & -1.25 & 0.0017 & -1.63 \\
\hline 10 & 7.20 & 2583.00 & 14.80 & 629.00 & 7.20 & 2581.13 & 14.80 & 628.00 & 0.0001 & 1.87 & -0.0015 & 1.00 \\
\hline 11 & 11.90 & 3943.00 & 13.10 & 964.00 & 11.90 & 3931.00 & 13.10 & 961.00 & -0.0016 & 12.00 & 0.0020 & 3.00 \\
\hline 12 & 15.00 & 5068.00 & 12.00 & 1243.00 & 15.00 & 5067.38 & 12.00 & 1243.63 & -0.0021 & 0.6250 & 0.0002 & -0.6250 \\
\hline 13 & 7.00 & 2477.00 & 15.00 & 591.00 & 7.00 & 2478.87 & 15.00 & 592.37 & -0.0021 & -1.87 & 0.0028 & -1.37 \\
\hline 14 & 12.30 & 4027.00 & 12.70 & 1002.00 & 12.30 & 4027.00 & 12.70 & 1001.63 & 0.0020 & 0.0000 & -0.0013 & 0.3750 \\
\hline 15 & 11.50 & 3763.00 & 13.50 & 923.00 & 11.50 & 3761.75 & 13.50 & 921.37 & 0.0023 & 1.25 & -0.0017 & 1.63 \\
\hline 16 & 15.20 & 5169.00 & 11.80 & 1278.00 & 15.20 & 5169.63 & 11.80 & 1277.75 & 0.0001 & -0.6250 & 0.0010 & 0.2500 \\
\hline 17 & 14.91 & 5073.00 & 12.30 & 1240.00 & 14.90 & 5071.13 & 12.30 & 1238.63 & 0.0021 & 1.87 & -0.0028 & 1.38 \\
\hline
\end{tabular}
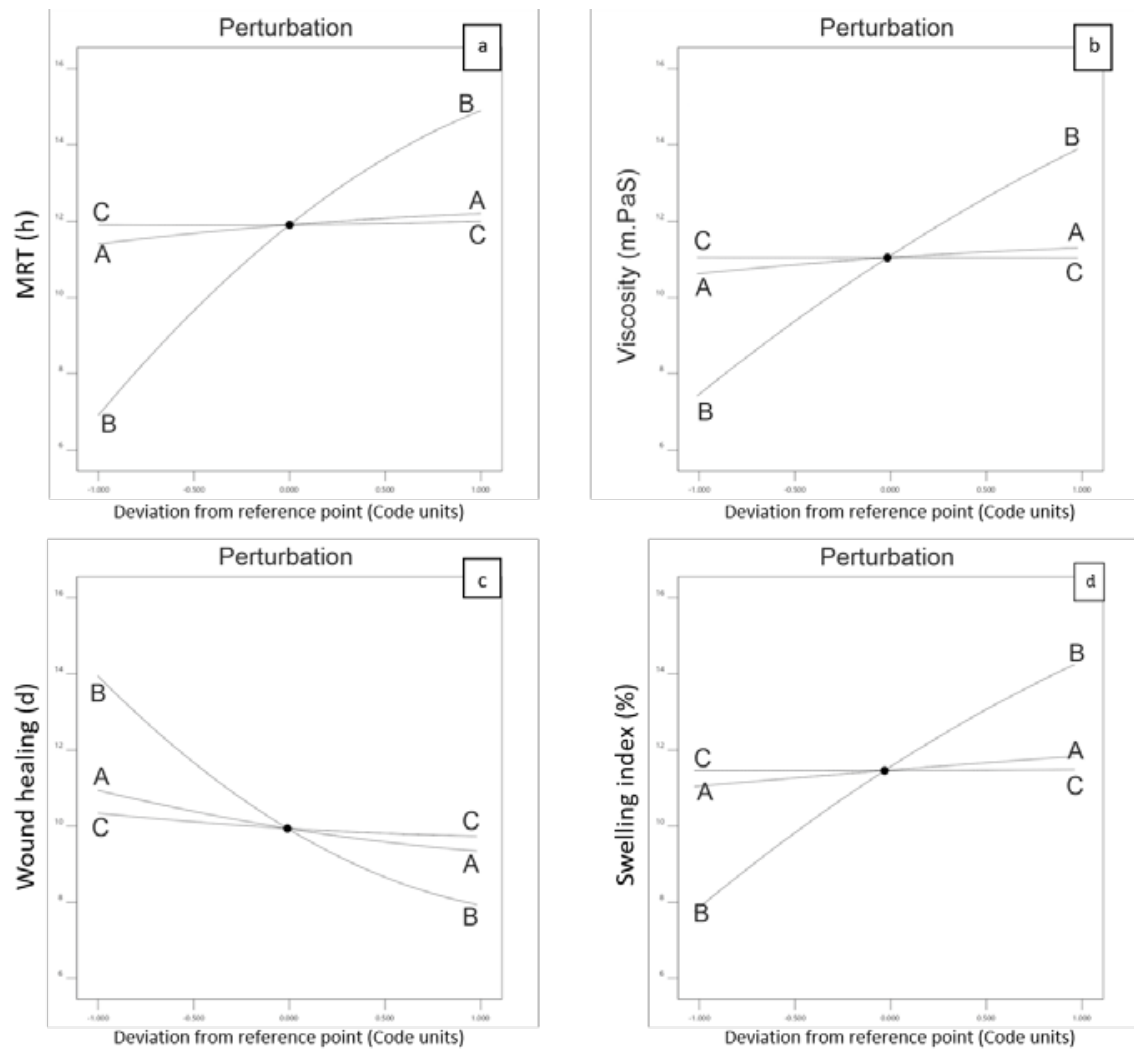

Fig. 2: The perturbation graph of (a) MRT, (b) Viscosity, (c) Wound healing, and (d) swelling index, showing the effect of factor A-HPMC B-PVP K30, and C-CNP concentration

MRT is the time taken by the nanogel formulation to release $80 \%$ of its active ingredient. The rate of release of Copper ions from nanogel depends on the concentration of HPMC, PVP K30 and CNPs concentration. The MRT of the nanogel increases with an increase in the concentration of PVP K30, with a slight increase in MRT with an increase in the concentration of HPMC. At a low level of PVP, the nature of nanogel is pseudo-gel-like, which increases the rate of drug release or decreases MRT. At low levels of HPMC, the ratio of PVP in the nanogel increases, which shifts the nature of nanogel towards true gel, resulting in a decrease in drug release rate or increase in MRT.

The viscosity of the nanogel is the fluid resistance to deformation at a given rate. The increase in the concentration of HPMC and PVP K30 will significantly increase the viscosity as compared to CNP conc. At low concentration of HPMC and PVP, the viscosity of nanogel is low due to less crosslinking and polymer chain entanglement.

Wound healing days is the measure of the days required for the complete healing of wounds. The wound healing days significantly reduced with an increase in the concentration of polymer HPMC and PVP K30. At low concentration, the wound healing days increase due to a reduction in moisture retention and sustain the release of copper ions by nanogel.

The swelling index is the ability of the polymer to absorb biological fluids. The swelling index of the nanogel increases at a high concentration of HPMC and PVP K30, due to an increase in cross-linking and polymer chain entanglement in the nanogel. At a low concentration 
of HPMC and PVP K30, the swelling index of the polymer is low due to limited cross-linking and polymer chain entanglement.

\section{Optimization of formulation using graphical optimization}

Optimization of nanogel was performed to determine the levels of factor A-C, which obtains $\mathrm{y} 1$ (MRT) in range of 10-24 h. y2 (viscosity) in range of 2312-3500 m. Pa. S, y3 (wound healing days) in range of 8-14 $d$ and $y 4$ (swelling index) in range of 1000-1300.

Under the predicted model for the required range of $\mathrm{y} 1-\mathrm{y} 4$, the required range of variables A, B, and C value of $0.396 \%, 2.558 \%$, and $0.2 \mu \mathrm{g} / \mathrm{ml}$ respectively, by utilizing the value of factor's 3 different batches of $100 \mathrm{~g}$ nanogel was prepared. The value of the observed responses y1-y4 was found to be in very close agreement with the predicted values. Thus, establishing the reliability of the optimization process. Fig. 3 represents the overlay plot of graphical optimization by DOE software for obtaining responses in the desirable range.

Finally, the optimized concentration of variable factors was found to be, HPMC (0.369), PVP K30 (2.581), and CNPs (0.2); the final optimized formulation is presented in table 9

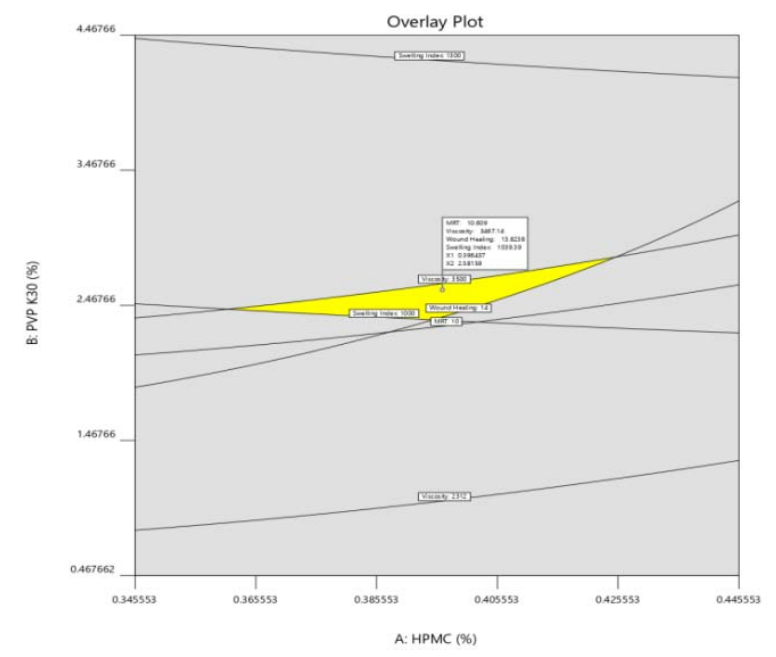

Fig. 3: Represents the overlay plot of MRT, viscosity, wound healing days, and swelling index for optimization parameter suggested by DOE software for the response in the desired range. Factors on X-axis = A: HPMC, Y-axis = B: PVP K30, actual factors $\mathrm{C}$ : $\mathrm{CNP}$ conc $=0.2$
Table 9: Final optimized formulation details

\begin{tabular}{lll}
\hline S. No. & Ingredients & Quantity (g) \\
\hline 1 & CNPs & 0.2 \\
2 & HPMC & 0.369 \\
3 & PVP K30 & 2.581 \\
4 & PEG 400 & 2.5 \\
5 & Distilled water & Quantity sufficient \\
& & for 50 g \\
\hline
\end{tabular}

\section{Wound healing study}

Burn wound (15 $\mathrm{mm}$ ) was created using a heated metal rod, on all animal shows significant variation in wound healing rate from the duration of the creation of wound to completion of the wound. $5^{\text {th }}$ and $14^{\text {th }}$ day of the study were selected for histological and biochemical evaluation due to significant phases of wound healing. The rate of wound closure was measured by calculating the percentage of wound closure (fig. 5), indicating significantly accelerated wound healing in CNG treated group as compared to the vehicle control and normal control group.

The wound closure was significantly higher as compared to vehicle control and normal control group, leading to complete closure of wound on $14^{\text {th }}$ day in CNG treated group.

\section{Histological analysis}

Histological evaluation of the burn tissue samples (fig. 4) on the completion of the study indicates the presence of exudate, reepithelization, leukocyte infiltration, and collagen deposition. Histological evaluation of the treated group shows significant low levels of inflammation, exudates, and collagen deposition leading to complete re-epithelization on the $14^{\text {th }}$ day.

\section{Inflammatory cytokines}

Evaluation of inflammatory cytokines IL-6, IL-10, and TNF- $\alpha$ were done on the $5^{\text {th }}$ and $10^{\text {th }}$ day of study. In fig. 4 on the $5^{\text {th }}$ day, the IL- $6(39.74 \%)$ and TNF- $\alpha$ (49.37\%) were significantly lower in the case of CNG treated groups as compared to $\mathrm{NC}$, indicating reduced inflammation, and in the case of IL-10 (30.90\%), the increased concentration of antiinflammatory cytokines resulted in reduced inflammation, which supports the outcome of histological evaluations [14].

Similarly, on the $14^{\text {th }}$ day, the reduced concentration of IL- 6 and TNF- $\alpha$ with decreased concentration of IL-10 indicates reduced inflammation and faster neutralization of the inflammatory phase, indicating completion of the wound healing process.

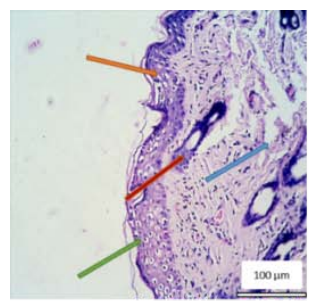

NC

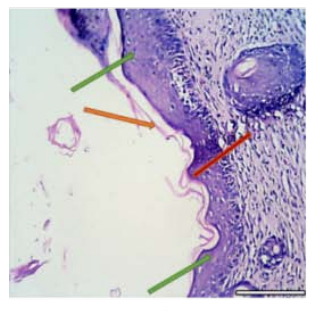

vc

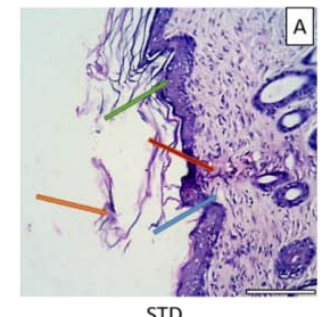

STD

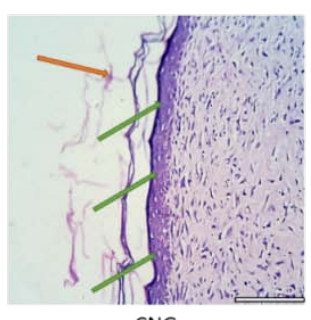

CNG

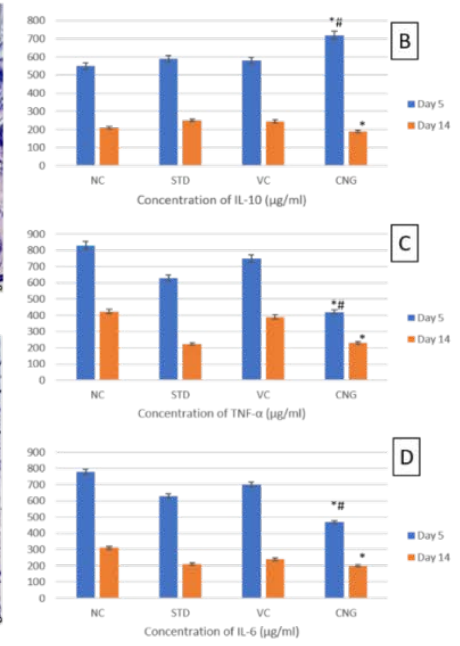

Fig. 4: (A) Histological evaluation at the burn wound site of different groups (400X) on the $14^{\text {th }}$ day of treatment. The presence of collagen deposition, leukocyte infiltration, exudate, and re-epithelization was indicated by blue, red, orange, and green, respectively. (B) concentration of IL-10, (C) concentration of TNF- $\alpha$, the (D) concentration of IL-6 on respective groups (NC, STD, VC, CNG) on the $5^{\text {th }}$ and $14^{\text {th }}$ day. All values are expressed as, $n=6$, mean \pm SD. ${ }^{*}=p<0.05$ vs. $N C, \#=p<0.05$ vs STD 


\section{Wound closure}

Wound closure rate was evaluated to determine the rate of wound healing. The percentage of wound closure $(12.27 \%)$ was evaluated on the $5^{\text {th }}$ day indicates significant wound closure, as compared to the NC group. Similarly, on the $14^{\text {th }}$ day of the wound closure $(100$ $\%$ ) is very much significant as compared to the NC group, indicating accelerated wound healing in CNG treated group, which supports the finding of histological evaluation. Copper nanoparticles will release copper ions in sustain manner, which will be primarily controlled by the concentration of copper nanoparticles, HPMC, and PVP [15] These factors in combination, will provide copper ions in optimized concentration, which will provide sufficient antibacterial property [16]. Moreover, HPMC and PVP will also control the moisture and oxygen permeability, providing an optimized environment for the body's natural immune system to remove necrotic tissue by phagocytosis and will provide a microenvironment of new cell generation [17].
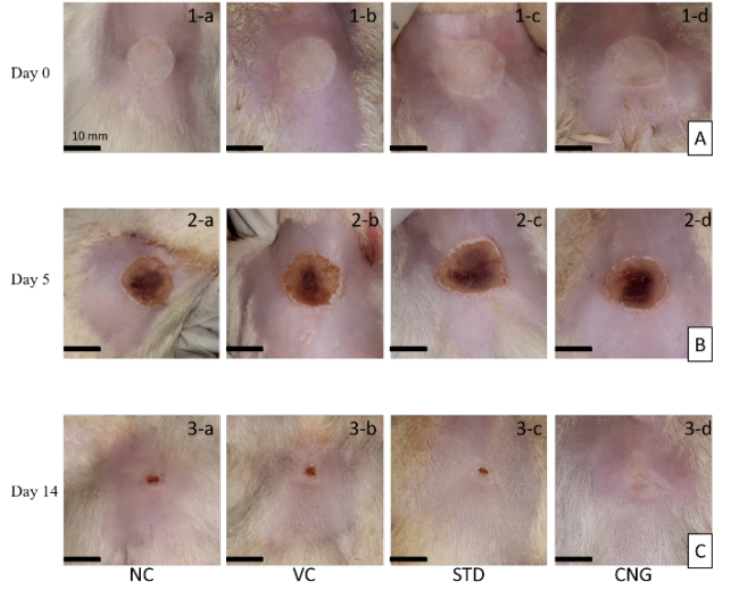

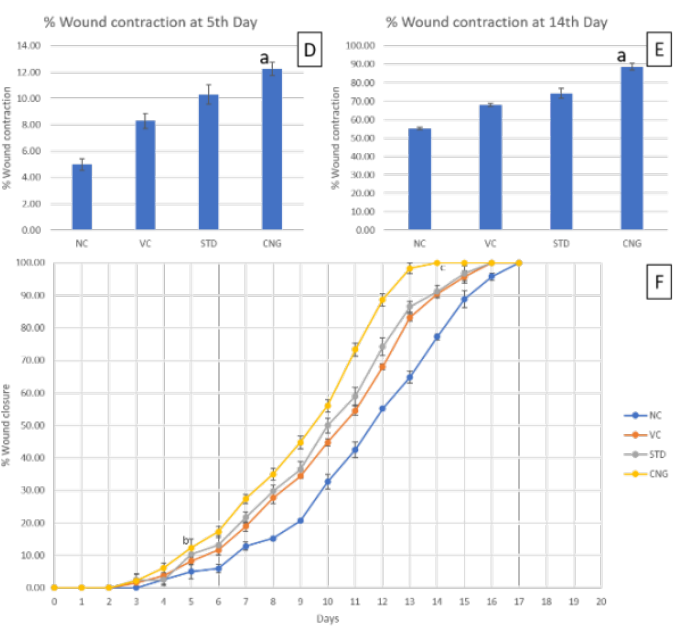

Fig. 5: Healing rate of burn wound by CNG was studied, (A) physical observation of burn wound on day 0 , (B) day 5, (C) day 14. (D) shows the percentage wound contraction of the group, NC, VC, STD, and CNG on day $14^{\text {th }}$. (F) show the percentage wound closure of group $\mathrm{NC}$, VC, STD, and CNG. All values are expressed as, $n=6$, mean \pm SD. $(a, b$, and $c=p<0.05$ vs NC)

\section{CONCLUSION}

Burns are physical injuries caused by exposure to excessive heat, which may result in blister formation. Burn wounds are very much complicated than excision wounds due to the deep penetration of heat into the tissue, which results in the damaging of additional tissue. This creates a zone of stasis in the adjacent healthy tissue, limiting the supply of essential elements required for the removal of dead tissue and the development of healthy tissue. On another hand, in the zone of stasis, due to limited circulation, cell apoptosis starts to take place. Leading to necrosis and scar formation. In our product, hydrogel will also form a flexible film on the outer side of the wound site, effectively controlling the moisture and providing a physical barrier against environmental conditions, which in combination with the antimicrobial and anti-inflammatory activity of copper nanoparticles results in scar-free, accelerated wound healing.

\section{ACKNOWLEDGMENT}

We are highly thankful to the founder president and Amity University, for providing lab space and facilitated to carry out this research.

\section{FUNDING}

This research did not receive any specific grant from any funding agencies

\section{AUTHORS CONTRIBUTIONS}

All the authors have contributed equally.

\section{CONFLICTS OF INTERESTS}

The authors declare that they have no competing financial interest

\section{REFERENCES}

1. Menna C, Calista N, Aurino L, Dwijayanti A. Aloe vera vs. Silver sulfadiazine for treating second-degree burn wounds: evidence-based case report. Int J Appl Pharm 2019;11:146-8.

2. Evers LH, Bhavsar D, Mailander P. The biology of burn injury. Exp Dermatol 2010;19:777-83.
3. Singh A. Hydrogel nanotubes with ice helices as exotic nanostructures for diabetic wound healing. Mater Horizons 2019;6:274-84.

4. Rose LF, Chan RK. The burn wound microenvironment. Adv Wound Care 2016;5:106-18.

5. Ferreira SLC. Box-behnken design: an alternative for the optimization of analytical methods. Anal Chim Acta 2007;2:179-86.

6. Taneja G, Sud A, Pendse N, Panigrahi A, Kumar A, Sharma AK Nano-medicine and vascular endothelial dysfunction: options and delivery strategies. Cardiovasc Toxicol 2019;19:1-12.

7. Nochos A, Douroumis D, Bouropoulos N. In vitro release of bovine serum albumin from alginate/HPMC hydrogel beads. Carbohydr Polym 2008;3:451-7.

8. Kumar A, Pandit V, Nagaich U. Therapeutic evaluation of chemically synthesized copper nanoparticles to promote full-thickness excisional wound healing. Int J Appl Pharm 2020;12:136-42.

9. Kamarudin NB, Sharma S, Gupta A, Kee CG, Chik SMSBT, Gupta R. Statistical investigation of extraction parameters of keratin from chicken feather using Design-Expert 3. Biotech 2017;7:1-9.

10. Sharma AK, Kumar A, Taneja G, Nagaich U, Deep A, Rajput SK Synthesis and preliminary therapeutic evaluation of copper nanoparticles against diabetes mellitus and-induced micro-(renal) and macro-vascular (vascular endothelial and cardiovascular) abnormalities in rats. RSC Adv 2016;6:36870-80.

11. Kim B, Peppas NA. In vitro release behavior and stability of insulin in complexation hydrogels as oral drug delivery carriers. Int J Pharm 2003;266:29-37.

12. Valdes 0. Methamidophos removal from aqueous solutions using a super adsorbent based on crosslinked poly(vinyl alcohol) hydrogel. J Appl Polym Sci 2018;5:45964.

13. Cai EZ. Creation of consistent burn wounds: a rat model. Arch Plast Surg 2014;41:317-24.

14. Hannestad J, Dellagioia N, Bloch M. The effect of antidepressant medication treatment on serum levels of inflammatory cytokines: a meta-analysis. Neroew 2011;36:2452-9.

15. Manyasree D, Peddi KM, Ravikumar R. CuO nanoparticles: synthesis, characterization and their bactericidal efficacy. Int J Appl Pharm 2017;9:71-4. 
16. Sharma AK. Combined and individual strategy of exercise generated preconditioning and low dose copper nanoparticles serve as superlative approach to ameliorate ISO-induced myocardial infarction in rats. Pharmacol Reports 2018;70:78995.
17. Sharma AK, Kumar A, Sahu M, Sharma G, Datusalia AK, Rajput SK. Exercise preconditioning and low dose copper nanoparticles exhibits cardioprotection through targeting GSK$3 \beta$ phosphorylation in ischemia/reperfusion induced myocardial infarction. Microvasc Res 2018;120:59-66. 